\title{
Corpo sem fim, escrita sem margem: a problematização da identidade feminina na narrativa de Silvina Ocampo
}

Body without end, writing without margin: the problematization of female identity in the Silvina Ocampo's narrative

Rafael Eisinger Guimarães

Universidade de Santa Cruz do Sul

DOI: https://doi.org/10.5902/2176148537581

Resumo: Este ensaio propõe-se a demonstrar como a escrita de Silvina Ocampo problematiza as ideias de corpo e identidade feminina construídas pelo imaginário androcêntrico, tomando como objeto os contos "Autobiografía de Irene”, publicado na obra homônima de 1948, e "El diario de Porfiria Bernal", que integra a obra Las invitadas, de 1961. Para empreender tal análise, será de fundamental importância a teorização levada a cabo por nomes como Elaine Showalter (1994), Hélène Cixous (1997), Luce Irigaray (2017), Lucía Guerra (2006), Nelly Richard (2003), Rita Terezinha Schmidt (2017), Simone de Beauvoir (2009) e Sherry Ortner (1979), dentre outros.

Palavras-chave: Corpo feminino. Identidade feminina. Crítica literária. Écriture féminine. Silvina Ocampo.

Abstract: This essay proposes to demonstrate how Silvina Ocampo's writing problematizes the idea of female's body and identity constructed by androcentric imaginary, taking as object the short tales "Autobiografía de Irene", published in the book with the same name in 1948, and "El diario de Porfiria Bernal", included in Las invitadas, published in 1961. To undertake such analysis, it will be of key importance the theorization carried out by scholars such Elaine Showalter (1994), Hélène Cixous (1997), Luce Irigaray (2017), Lucía Guerra (2006), Nelly Richard (2003), Rita Terezinha Schmidt (2017), Simone de Beauvoir (2009) e Sherry Ortner (1979), among others.

Key words: Female body. Female identity. Feminist criticism. Écriture féminine. Silvina Ocampo. 
Rafael Eisinger

Guimarães

200

\section{Introdução}

A obra da argentina Silvina Inocencia Ocampo Aguirre, fruto de uma dedicação de mais de cinco décadas à literatura, reúne, além de uma dezena de livros de poesia, quatro livros de contos para o público infantil e dois romances: Los que aman, odian, de 1946, escrito em parceria com seu esposo, Adolfo Bioy Casares, e La torre sin fin, publicado em 2007. Somam-se a essa lista, sete livros de contos - Viaje olvidado, de 1937; Autobiografía de Irene, de 1948; La fúria, de 1959; Las invitadas, de 1961; Los días de la noche, de 1970; Y así sucessivamente, de 1987; e Cornelia frente al espejo, de 1988 -, nos quais a presença marcante do fantástico, do onírico e da ambiguidade configura-se como um dos traços mais característicos. Na quase totalidade das cerca de duzentas narrativas curtas que escreveu, Silvina Ocampo traz para o centro a experiência feminina, seja a partir de narradoras, muitas vezes meninas, seja a partir de protagonistas mulheres. Em tais textos, mais que simplesmente retratar o cotidiano dessas personagens, a escritora argentina apresenta, via de regra, o feminino como um elemento de subversão e problematização dos preceitos e das premissas da cultura patriarcal e do imaginário androcêntrico.

Para verificar tal questão de forma mais profunda, selecionei para esta análise as narrativas "Autobiografía de Irene", do livro homônimo, de 1948, e "El diario de Porfiria Bernal", publicado em Las invitadas, de 1961. A despeito de suas particularidades em termos de trama e forma, os dois contos estabelecem um interessante diálogo, uma vez que ambos apresentam personagens femininas que se valem do ato de narrar para refletir sobre sua identidade. Assim, tendo como objetivo analisar de que forma a escrita de Silvina Ocampo problematiza as concepções de corporeidade e de identidade feminina construídas pela racionalidade patriarcal, buscarei demonstrar como a narrativa/escrita de si constitui uma forma de as personagens femininas se apropriarem de sua identidade, assumindo um papel de sujeito, historicamente atribuído ao masculino, para construírem uma subjetividade que rompe com as concepções patriarcais e binárias a respeito do corpo e da identidade, a partir de um apagamento dos limites da corporalidade e das fronteiras entre o "eu" e o "outro".

Cruciais para a interpretação que pretendo construir no presente ensaio, as considerações de Simone de Beauvoir (2009), Sherry Ortner (1979), Luce Irigaray (2017), Hélène Cixous (1976) e Nelly Richard (2003), dentre outras, sobre a figuração do feminino, em especial o papel que 
a aproximação entre feminino, natureza e corporalidade desempenhou como forma de subjugação das mulheres na cultura patriarcal, bem como as concepções acerca das características da escrita de autoria feminina, constituem a base teórica para este trabalho, e é a partir da discussão de tais conceitos que eu inicio a minha reflexão.

\section{As relações entre o corpo e o feminino no pensamento ocidental}

A consolidação do feminismo como campo epistemológico nos âmbitos político e acadêmico, e como matriz teórica para uma crítica à cultura androcêntrica teve, durante seu desenvolvimento, dentre outras características marcantes, o que se pode chamar de uma "relação conturbada" com a questão da corporeidade. Visto como ponto nevrálgico para

Corpo sem fim, escrita sem margem o processo de inferiorização do feminino por parte do discurso e do imaginário patriarcais, o corpo foi, por muito tempo, tido como uma espécie de obstáculo a ser superado pelo movimento feminista, premissa resumida na afirmação emblemática de Simone de Beauvoir do final da década de 1940: "ninguém nasce mulher: torna-se mulher" (BEAUVOIR, 2009, p. 361). A despeito do esforço inicial em desviar-se de tal tópico, os debates acerca das aproximações e dos distanciamentos entre o feminino e a corporalidade (bem como as ideias correlatas de natureza e sexo) foram retomados menos de três décadas depois, tornando-se pauta constante das reflexões na área, como é possível atestar pelos títulos de alguns dos textos mais lidos e discutidos desse período, tais como os artigos Is female to male as nature is to culture?, escrito por Sherry Ortner em 1972, e Le rire de la Méduse, publicado em 1975 por Hélène Cixous, além do livro Ce sexe qui n'en est pas un, de Luce Irigaray, editado em 1977 , só para mencionar algumas obras.

$\mathrm{Na}$ esteira de tal guinada, mais que problematizar as oposições hierárquicas construídas entre o masculino e o feminino, a mente e o corpo, a cultura e a natureza etc., que há séculos sustentam o pensamento sexista ocidental, a crítica feminista tem buscado sublinhar e discutir as origens daquilo que Beauvoir identificou como "uma pretensão original [do sujeito masculino] ao domínio sobre o Outro" (BEAUVOIR, 2009, p. 92), ou, mais precisamente, valendo-me do argumento de Virginia Woolf, dissecar os meandros do que a escritora inglesa apontou como sendo uma estratégia para erigir uma pretensa superioridade inata do homem a partir de uma também pretensa in- 
Rafael Eisinger

Guimarães

ferioridade inata da mulher (WOOLF, 1990, p. 44). Dialogando com o clássico de Beauvoir, publicado 23 anos antes, Sherry Ortner (1979) dá indícios do mecanismo a partir do qual se constrói e se sustenta, como fato universal, o caráter secundário do feminino, sendo tal artifício justamente o de relacionar o feminino àquilo que, em todas as culturas, é visto como algo inferior, algo a ser dominado e suplantado, a saber, a natureza. Como bem sublinha a antropóloga estadunidense, o corpo é um elemento-chave para essa construção, na medida em que a fisiologia feminina não apenas pretensamente aproxima a mulher da natureza como também lhe impõe papéis sociais vistos como culturalmente inferiores, tais como os cuidados com a casa e a prole, os quais, por sua vez, estão relacionados a uma estrutura psíquica igualmente vista como mais relacionada à natureza.

Se, como quer a autora de 0 segundo sexo, "o corpo [é] o instrumento de nosso domínio do mundo" (BEAUVOIR, 2009, p. 65), é imprescindível atentarmos para a forma como as questões biológicas são transplantadas para a esfera sociocultural, adquirindo, nesse processo, significados bastante precisos, sobretudo a partir de uma série de imagens e metáforas associadas ao feminino. Para além das ideias intimamente relacionadas à physis, tais como a referência ao elemento da água, à terra fecunda ou à Mãe Natureza - todas remetendo ao atributo biológico da reprodução -, outros signos se unem nesse complexo e intencional jogo de associações que distancia a mulher da esfera da cultura e da transcendência, como é o caso da concepção do feminino como lacuna. No que concerne a essa questão, Luce Irigaray (2017), revisitando as concepções freudianas sobre a sexualidade feminina, questiona o postulado de que a corporalidade da mulher e, por extensão, sua libido e seu prazer sejam marcados pela falta e pela atrofia, ideia que transpõe, sem qualquer mediação, a "invisibilidade" do aparelho sexual feminino para uma "ausência" constituinte da psique feminina, ausência essa que estaria na origem do conceito de "inveja do pênis". Semelhante crítica já havia sido feita por Simone de Beauvoir (2009) em relação à visão que Freud constrói da mulher como um "homem mutilado", que, a partir de uma pretensa "inexistência" em termos de fisiologia sexual, projetaria sua libido no falo masculino. Apesar da consistência com que tal visão se arraigou ao imaginário patriarcal, tanto Beauvoir quanto Irigaray demonstram seu caráter de constructo social. 
Paralelamente a essa ideia de incompletude, a concepção patriarcal do feminino reveste-se de um segundo aspecto simbólico que, em larga medida, decorre da percepção do corpo da mulher como um elemento da natureza ao dispor da cultura, esta entendida aqui como uma força masculina. Trata-se da visão da mulher como objeto ou, mais que isso, como propriedade do homem. Em seu extenso e detalhado inventário do que chamou de mitos construídos em torno da mulher, Beauvoir destaca a ideia da beleza como um atributo definidor da feminilidade, tal como esta é concebida na cultura ocidental. Assim, como lembra a filósofa, “[o] ideal da beleza feminina é variável; mas certas exigências permanecem constantes. Entre outras, exige-se que seu corpo ofereça as qualidades inertes e passivas de um objeto, porquanto a mulher se destina a ser possuída" (BEAUVOIR, 2009, p. 229). Para além do efeito de moldar a corporalidade

Corpo sem fim, escrita sem margem feminina segundo um padrão de beleza que, via de regra, atende às expectativas de um sujeito masculino, os adornos e as imposições estéticas, tais como o uso de sapatos de salto alto e vestidos justos, por exemplo, limitam a mobilidade do corpo feminino e, nesse sentido, contribuem para aprisionar a mulher na esfera da imanência e da passividade, cabendo ao masculino o espaço da transcendência e da atividade.

Objeto belo, feito para ser admirado conforme os ditames patriarcais, o corpo da mulher também é tido como mercadoria, como propriedade, como algo que deve ser conquistado e, uma vez que isso ocorra, tornar-se posse daquele que o conquistou. Nessa lógica, a esposa torna-se um "tesouro" que deve, ao mesmo tempo, ser exibido e protegido da "cobiça alheia". Nesse contexto, como nos lembra Simone de Beauvoir:

A "boa esposa" é para o homem o mais precioso dos tesouros. Pertence-lhe tão profundamente que participa da mesma essência: ubi tu Gaius, ego Gaia; usa o nome dele, tem os mesmos deuses, ele é responsável por ela: chama-a sua metade. Ele orgulha-se de sua mulher como de sua casa, suas terras, seus rebanhos, suas riquezas, e por vezes mais ainda; é através dela que manifesta sua força aos olhos do mundo; ela é sua medida e sua parte na terra (BEAUVOIR, 2009, p. 251).

Em direção semelhante vai Luce Irigaray ao detalhar a forma como o corpo da mulher assume o status de mercadoria: 
[T]odos os sistemas de trocas que organizam as sociedades patriarcais, e todas as modalidades de trabalho produtivo que são reconhecidas, valorizadas, remuneradas nessas sociedades, são negócios de homens. Mulheres, signos, mercadorias são sempre remetidos ao homem (quando um homem compra uma mulher, é ao pai dela ou ao irmão que ele "paga", e não à mãe), e eles passam sempre de um homem a outro homem, de um grupo de homens a outro grupo de homens (IRIGARAY, 2017, p. 192).

Rafael Eisinger

Guimarães

E, nesse "mercado de mulheres", destaca Irigaray, a exemplo do que já havia sido referido por Beauvoir, o valor de produto do corpo feminino está diretamente relacionado ao trabalho do homem, seja o pai da noiva, seja o marido, reproduzindo, com novas tintas, a ideia de que a mulher é um corpo "natural" a ser dominado e moldado pela cultura masculina.

A partir dessa profunda revisão do processo de estereotipização e subvalorização do feminino levado a cabo pelo pensamento patriarcal, a crítica feminista contemporânea, na esteira da reflexão instaurada por pensadoras como Beauvoir e Ortner, dentre outras, tem retomado as discussões em torno da corporalidade feminina, entendendo-a não como um fato biológico incontornável, mas como algo em constante elaboração. Nesse sentido, Elizabeth Grosz (2000) defende a substituição dessa concepção essencialista por um conceito de corporeidade não dada, mas construída, fortemente afetada tanto por questões psicológicas internas quanto por fatores externos culturais e sociais. Na mesma direção vai o pensamento de Rita Terezinha Schmidt ao sublinhar o fato de que "o significado cultural do corpo feminino não se reduz à referencialidade de um ser empírico de carne $\mathrm{e}$ osso, mas constitui um constructo simbólico, produzido e reproduzido na cultura e na sociedade ocidental ao longo dos tempos" (SCHMIDT, 2017, p. 391-392). E é justamente a consciência desse status ficcional que marca a ideia de mulher propalada pela cultura hegemônica o que impulsiona a teoria feminista não apenas a problematizar os pressupostos já referidos, como também a conceber o corpo, na esteira das proposições de Lucía Guerra, como "un modo de estructuración que afectaría sistemas tan diversos como el lenguaje, la base económica y la filosofía" (GUERRA, 2006, p. 145). 
Em meio a todos os aspectos que emergem dessa reapropriação do corpo pelas mulheres, destaca-se o questionamento com relação a seu caráter estático e fechado. Nesse sentido, lembra Luce Irigaray, a corporalidade feminina instaura uma ruptura na lógica patriarcal, apresentando-se como algo plural e sem contornos:

\begin{abstract}
Daí o mistério representado por ela em uma cultura que tem a pretensão de enumerar tudo, de tudo classificar por unidades, de inventariar tudo por individualidades. Ela não é uma nem duas. Não se pode, rigorosamente, determiná-la como uma pessoa, e muito menos ainda como duas (IRIGARAY, 2017, p. 36, grifo da autora).
\end{abstract}

Tal inadequação à singularidade e à imposição de limites, tal subversão ao que Lucía Guerra chama de modalidade hermética do feminino, vista como "una expresión de la territorialidad patriarcal que hace de la mujer una zona estática y cerrada" (GUERRA, 2006, p. 55), encontra na linguagem, conforme ressalta a pensadora chilena, a sua principal forma de materialização, tal como demonstram, em especial, as reflexões da crítica feminista de matriz francesa acerca do conceito de écriture féminine.

\section{A escrita de autoria feminina como subversão do corpo imaginado pelo patriarcado}

Partindo da premissa de que a experiência de gênero é algo determinante para a nossa compreensão do mundo e para a nossa relação com as coisas, os fatos e as pessoas que nos cercam, parece bastante aceitável que, para além de uma perspectiva essencialista, consideremos a existência de diferenças mais ou menos explícitas na produção literária de escritores e escritoras. Isso posto, torna-se incontornável à crítica literária de matriz feminista a busca por um levantamento e uma compreensão das peculiaridades que marcam a autoria feminina. Na tentativa de encontrar respostas para essas questões, Elaine Showalter (1994) propõe quatro categorias de diferença envolvidas nos textos de mulheres, as quais representariam as distintas tendências da crítica feminista ginocêntrica ${ }^{1}$, a saber: biológica, linguística, psicanalítica e cultural.

1 Os termos "crítica feminista ginocêntrica" e "ginocrítica" foram cunhados por Showalter (1994) para marcar a diferença entre o trabalho de leitura da construção da figura feminina em textos de autoria masculina - que predominava nos estudos feministas até os anos 1970 - e o trabalho de interpretação dos textos de autoria feminina, os quais, por suas peculiaridades, não poderiam valer-se da reflexão teórica que sustentava a análise das obras literárias escritas por homens.
Corpo sem fim, escrita sem margem 
Rafael Eisinger

Guimarães

206

Como fica bastante claro na exposição da pensadora estadunidense, estabelece-se uma hierarquia entre esses conceitos, na medida em que "uma teoria da cultura incorpora ideias a respeito do corpo, da linguagem e da psique da mulher, mas as interpreta em relação aos contextos sociais nos quais elas ocorrem" (SHOWALTER, 1994, p. 32). Em um indisfarçável desapreço aos três elementos que fundamentam o feminismo francês de Cixous e Irigaray, a proposta de Showalter dá indícios de uma concepção a partir da qual as instâncias corporal, discursiva e psicológica são vistas como matéria inerte, sendo determinadas, em um processo de mão única, pelo contexto no qual estão inseridas. Em franca oposição a tal visão e aproximando-me bastante dos argumentos de Arleen Dallery (1997), compreendo aqui - como acredito ter já deixado claro - o corpo não apenas como um constructo em constante processo de elaboração, processo esse atravessado tanto por fatores externos e culturais quanto por fatores internos e psíquicos, mas também como um elemento de ação política, que afeta o contexto na mesma medida em que é afetado por ele.

Tido como um dos textos-base para a reflexão acerca da écriture féminine, o artigo Le rire de la Méduse, de Hélène Cixous, reivindica a criação, por parte das mulheres, de uma escrita que não apenas subverta a hegemonia discursiva patriarcal, mas que faça isso valendo-se de uma retomada e de uma revalorização do corpo feminino:

\footnotetext{
If woman has always functioned "within" the discourse of man,

[...] it is time for her to dislocate this "within," to explode it, turn it around, and seize it; to make it hers, containing it, taking it in her own mouth, biting that tongue with her very own teeth to invent for herself a language to get inside of (CIXOUS, 1976, p. 887).
}

Com uma força talvez apenas comparada à frase "ninguém nasce mulher: torna-se mulher", proferida por sua conterrânea, a conclamação de Cixous "as mulheres devem escrever através de seus corpos" (CIXOUS, 1976, p. 886, tradução minha) propõe uma concepção de corporalidade não apenas como fruto da experiência do feminino - o "corpo vivido" de que nos fala Beauvoir -, mas como local e fonte de sua escrita, da expressão e da construção dessa experiência, desse "tornar-se mulher". Guinada radical na trajetória epistemológica do feminismo, o posicionamento de Hélène Cixous e de Luce Irigaray, dentre outras representantes do feminismo francês, foi subversivo não apenas por trazer ao primeiro plano a 
questão do biológico, mas, sobretudo, por problematizar a linguagem tal como é concebida pelo pensamento ocidental. Ao constituírem-se como sujeitos, reivindicando uma voz própria, as mulheres, como nos lembra Irigaray, desorganizam a lógica e o discurso dos homens, desestabilizando o funcionamento da linguagem (masculina). Tal ruptura, sublinha a autora, deve-se ao fato de essa "fala-mulher" estar intimamente relacionada à corporeidade feminina, a qual é regida por "uma outra economia, que desvia a linearidade de um projeto, confunde o objeto-meta de um desejo, faz explodir a polarização sobre um único gozo, desordena a fidelidade a um único discurso..." (IRIGARAY, 2017, p. 39-40).

Posto que as mulheres escrevem através dos seus corpos, e sendo esses compreendidos como algo plural, não dado, não estático e não fechado, a escrita de autoria feminina apresenta, sim, traços bastante

Corpo sem fim, escrita sem margem peculiares que a distinguem da autoria masculina ${ }^{2}$. No entanto, é importante insistir aqui, não se trata de uma concepção essencialista - a partir da qual homens e mulheres escrevem de forma diferente porque têm corpos e sexos distintos -, mas sim da ideia de que a écriture féminine é, ao fim e ao cabo, uma estratégia, um recurso estilístico para expressar uma lógica e uma ontologia outras, distintas da patriarcal. É nessa direção que vai, por exemplo, o pensamento de Nelly Richard ao defender a ideia de "feminização da escrita", a qual rompe com os princípios masculinos da contenção e da unidade, extravasando toda sua heterogeneidade e pluralidade, podendo esse traço ser encontrado em um texto escrito tanto por uma mulher quanto por um homem. Assim, lembra a pensadora chilena:

Qualquer literatura que se pratique como dissidência da identidade, a respeito do formato regulamentar da cultura masculino-paterna, assim como qualquer escrita que se faça cúmplice da ritmicidade transgressora do feminino-pulsátil, levaria o coeficiente minoritário e subversivo (contradominante) do "feminino" (RICHARD, 2003, p. 133, grifo da autora).

2 A despeito do que as denominações "escrita de autoria feminina" e "escrita de autoria masculina" possam levar a crer, insisto que os argumentos aqui expostos desviam de qualquer concepção essencialista. Nesse sentido, em consonância com o que já destacaram pensadoras como Nelly Richard (2003), é possível identificar características próprias da écriture féminine em obras escritas por homens, da mesma forma que o fato de estarmos diante de um texto assinado por uma mulher não é "garantia" de que a obra apresente os traços aqui elencados. 
Rafael Eisinger

Guimarães

208
Embora Nelly Richard busque se descolar claramente do aspecto biológico - desviando, nesse sentido, das concepções de Cixous e Irigaray -, suas premissas alinham-se em muitos aspectos à concepção das pensadoras francesas, especialmente se lembrarmos que a autora de Le rire de la Méduse afirma que tal escrita "will always surpass the discourse that regulates the phallocentric system; (...). It will be conceived of only by subjects who are breakers of automatisms, by peripheral figures that no authority can ever subjugate" (CIXOUS, 1976, p. 883). Por sua vez, Luce Irigaray claramente compartilha da concepção de sua conterrânea ao afirmar que a linguagem falocêntrica aprisiona a mulher, um ser cujo corpo foi feito para mudanças constantes (IRIGARAY, 2017, p. 242), valendo-se, nessa reflexão, da metáfora do fluido como sendo um atributo feminino, em oposição ao sólido, que "mantém relações antigas com a racionalidade, às quais os fluidos não cessam de fazer objeção" (IRIGARAY, 2017, p. 131).

Paralelamente aos traços de fluidez e excesso, que podem ser tomados como definidores dessa "feminização" da escrita, outro aspecto, igualmente relacionado à experiência do feminino e a sua relação com a corporalidade, marca o que aqui chamamos de écriture féminine. Refiro-me ao que Cixous identificou como o caráter bissexual do feminino. Longe de remeter à ideia de libido, a bissexualidade de que fala a pensadora francesa diz respeito a uma abertura à alteridade e a um apagamento das fronteiras entre o eu e o outro, em uma explícita oposição à angústia de posse - paternidade, patrimônio, autoria - que marca a concepção de masculino própria do patriarcado. Tal aspecto é também sublinhado por Luce Irigaray, que aponta não apenas para a porosidade dos limites que separam o eu do outro, mas também para a inexistência de uma hierarquia a reger essa abertura para a alteridade: "você não está em mim. Eu não te contenho e nem te retenho (...). Entre nós, uma não é a 'verdadeira', a outra, sua cópia; uma não é o(a) original, a outra, o seu reflexo" (IRIGARAY, 2017, p. 244, grifos da autora).

A partir de uma noção que rompe de forma radical com as premissas falocêntricas de limite e hierarquia - "body without end, without appendage, without principal 'parts"' (CIXOUS, 1976, p. 889) -, o caráter "bissexual" do feminino, quando materializado na escrita, traduz-se em marcas textuais de descentramento, heterogeneidade e ruptura com as noções de unicidade e enclausuramento da subjetividade. Muito embora tais aspectos, conforme argumenta Nelly Richard, devam ser entendi- 
dos para além de uma vinculação essencialista entre corpo e escrita - e nesse sentido a écriture féminine não seria uma prerrogativa exclusiva do sexo feminino -, não se pode ignorar que tal questão, eminentemente estilística e discursiva, advém de uma experiência, de uma visão de mundo e de uma constituição de sujeito feminino marcadas, dentre outras coisas, pela diferença biológica e sexual, pela diferença corporal. Mais que isso, dar protagonismo ao corpo, retirando-o da sombra a que foi relegado por tanto tempo pela literatura canônica patriarcal - que, como sabemos, elevava as questões da razão e da esfera pública, e não a corporalidade e o privado, ao patamar de temática de valor universal -, configura, no caso da autoria feminina, um ato político. Nesse sentido, a escrita através do corpo, como quer Hélène Cixous, torna-se algo indissociável da (re)escrita do seu corpo, problematizando as concepções

Corpo sem fim, escrita sem margem hegemônicas que o pensamento ocidental construiu acerca destes dois elementos: o corpo e a escrita. Tais aspectos são postos em primeiro plano em muitos dos contos de Silvina Ocampo, em especial em "Autobiografía de Irene" e "El diario de Porfiria Bernal", nos quais, como procurarei demonstrar agora, a subversão de uma premissa patriarcal com relação à corporeidade e à subjetividade feminina torna-se não apenas o tema central da narrativa, mas também elemento estruturante de sua escrita.

\section{A (re)escrita de si nas personagens femininas de Silvina Ocampo}

A exemplo de muitos dos textos ficcionais elaborados por Silvina Ocampo ao longo de seus mais de cinquenta anos de carreira, os dois contos em análise aqui apresentam elementos que fogem às narrativas de teor realista, como é o caso do dom de premonição apresentado por Irene e dos episódios ocorridos no texto publicado em 1961, inexplicáveis a partir de uma lógica racional e cartesiana. Além disso, mais que apresentar, como seus títulos já deixam claro, personagens femininas no papel de protagonistas ou, mais precisamente, de narradoras autodiegéticas, ambos os contos, como também se depreende de seus títulos, trazem para o primeiro plano o ato de escrita dessas personagens como instrumento de autorreflexão e construção da própria subjetividade. Esse aspecto, por si só problematizador em um contexto cultural que, via de regra, destina ao feminino o papel de objeto narrado e raramente o de sujeito do discurso, revela-se 
Rafael Eisinger

Guimarães

ainda mais instigante na medida em que a narrativa elaborada por elas subverte também na forma, já que temos um conto circular em “Autobiografía de Irene" e dois relatos em contraponto em "El diario de Porfiria Bernal".

Um dos aspectos que merece destaque nos textos aqui em foco com relação à corporalidade feminina é o fato de eles, cada um a seu modo, colocar em xeque algo reiteradamente apresentado como um atributo da mulher: a beleza. No conto publicado em 1948, por exemplo, o embelezamento do corpo da protagonista configura um rito de transição da infância para a fase adulta, uma mudança que tem na morte do pai seu elemento instaurador:

\footnotetext{
La repentina muerte de mi padre determinó un cambio en mi vida. Mi infancia terminaba. Trataba de pintarme los labios y de usar tacos altos. En la estación los hombres me miraban, y tenía un pretendiente que me esperaba los domingos, a la salida de la iglesia. Era feliz, si es que existe la felicidad. Me complacía en ser grande, en ser hermosa, de una belleza que algunos de mis parientes reprobaban (OCAMPO, 2007, p. 162).
}

Diante do que se lê nesse excerto, é possível observar que Irene, à primeira vista, parece reproduzir o estereótipo a partir do qual o corpo feminino, voltado às atividades reprodutivas, deve ser belo e atraente para os homens, na qualidade de objeto a ser desejado, conquistado e possuído pelo masculino. Nesse sentido, tendo em vista a concepção de violência simbólica de Pierre Bourdier (2002), pode-se inclusive questionar a pretensa autonomia da personagem expressa na afirmação do prazer experimentado por ser grande e bonita. Contudo, creio ser arriscado ignorar o detalhe sutil de que esse embelezamento do corpo da jovem é motivo de reprovação por parte de alguns familiares, e que tal atitude, na medida em que ela tem ciência do incômodo que causa, pode representar um ato de contestação, um uso do corpo como provocação.

A seu modo, "El diario de Porfiria Bernal" também instaura uma problematização em torno desse tema, em especial a partir das reflexões que Antonia Fielding, moça inglesa contratada para cuidar da educação de Porfiria, desenvolve acerca de si mesma e da menina. 
Soy silenciosa y tal vez por ese motivo no parezco alegre como lo soy en realidad, o más bien lo fui. Para los que me ven de lejos soy hermosa: en el espejo aprecio lo necesaria que es la distancia para embellecer la asimetría de una cara. Frente a un espejo, en la infancia, deploré, llorando, mi fealdad (OCAMPO, 2007, p. 461).

Porfiria no era hermosa, no se parecía a su madre, pero hay una belleza casi oculta en los seres, que presentimos difícilmente si no somos bastante sutiles; una belleza que aparece y desaparece Corpo sem fim, escrita sem y que los vuelve más atrayentes: Porfiria tenía esa modesta y recatada belleza, que vemos en algunos cuadros de Botticelli, y margem esa apariencia de sumisión, que me engañó tanto en el primer momento (OCAMPO, 2007, p. 464).

Ao observar atentamente a concepção apresentada pela personagem, salta aos olhos a associação, já sublinhada por Beauvoir (2009), entre beleza e submissão feminina, seja no caso de sua autoavaliação como uma mulher silenciosa, seja na falsa impressão que ela teve com relação ao caráter submisso de Porfiria. Contudo, Antonia revela ter uma visão não plana acerca da beleza, tomando-a como um critério carregado de subjetividade e passível de significativa relativização. Ao falar sobre si, por exemplo, muito embora relate que, quando se olha de perto no espelho, seu rosto apresenta um aspecto que a levava às lágrimas na infância, ela demonstra considerar-se uma mulher que, a distância, pode ser vista como bela. Dito de outra forma, o que me parece estar por trás das palavras da personagem é uma concepção da beleza como algo que, se tomado como parâmetro avaliativo do feminino, é ilusório, pois algumas pessoas que, como ela, aparentam ser belas e silenciosas, quando revelam mais de sua personalidade, quando são "vistas de perto", podem frustrar as expectativas construídas. Constatação semelhante pode ser feita a partir da avaliação que a personagem faz da menina que ficará sob sua tutela. Para a mulher inglesa, a criança não é propriamente bonita - e aqui é importante destacar o fato de Ana María Bernal, mãe de Porfiria, representar o padrão de beleza assumido por Antonia -, muito embora aparente ter uma "beleza quase oculta", mais "pressentida" do que vista. Assim, seja pelo fato de a menina não revelar sua beleza, seja por ela mesma ter o que se pode chamar de uma 
Rafael Eisinger

Guimarães

212

beleza "falsa", na medida em que é percebida apenas de longe, as ideias de Antonia Fielding instauram fissuras na concepção simplificada e objetificante da beleza como um atributo da corporalidade feminina construída como algo ao dispor do sujeito masculino.

Se Antonia propõe uma visão mais complexa sobre a preponderância da beleza do corpo como elemento constituinte do gênero feminino, na mesma direção vai o pensamento de Porfiria Bernal, que toma o quesito inteligência como motivo para distanciar-se de sua mãe, a bela Ana María, e identificar-se com sua tutora:

- Mi diario, es un diario muy especial. Tal vez un día se lo entregue para que lo lea. Pero se lo entregaré a usted solamente. Mamá no lo tiene que ver porque a ella le parecería inmoral. La miré con asombro. ¿Cómo se atrevía a hablarme así?

- ¿Por qué le parecería inmoral a su madre y no a mí? -le pregunté con una ansiedad mal disimulada.

- Porque usted, Miss Fielding, es inteligente y sobre todo porque usted no es mi madre. Las madres fácilmente dejan de ser inteligentes (OCAMPO, 2007, p. 466).

Embora, no transcorrer da trama, Porfiria acabe por desenvolver também uma repulsa em relação a Miss Fielding, a valorização da inteligência em detrimento da beleza configura uma reprodução, por parte daquela, do discurso manifestado por esta: "Miss Fielding piensa que no soy hermosa, pero que tengo una expresión fugitivamente hermosa. 'Es la expresión de la inteligencia' me ha dicho. 'Es lo único importante" (OCAMPO, 2007, p. 468). E é justamente a partir desse parâmetro valorativo - ausência de beleza e presença de inteligência - que Porfiria constrói sua identidade em um movimento que se distancia da progenitora e se aproxima da tutora, mesmo que em seu discurso a menina manifeste um estranhamento às duas mulheres.

Essa aproximação entre Antonia Fielding e Porfiria Bernal materializa-se em uma reiterada presença do elemento do duplo na narrativa, o qual pode ser percebido na própria estrutura do conto, composto por dois relatos que se complementam ao mesmo tempo em que se contrapõem, mas principalmente pelo fato de a moça incentivar a menina a escrever um diário, reproduzindo algo que havia feito em sua infância. Mais que uma sugestão singela, a escrita do diário configura-se como 
uma oportunidade de autorreflexão e de construção da identidade por parte de Porfiria, processos esses em que a influência de Antonia Fielding se faz presente de forma muito clara:

\begin{abstract}
Miss Fielding me dio la idea de escribir este diario. Antes de conocerla no se me hubiera ocurrido: antes de conocerla no se me hubiera ocurrido contemplar los ángeles de Botticelli ni mi cara en tantos espejos, porque siempre encontré que yo era horrible y que mirarme en un espejo era un pecado (OCAMPO, 2007, p. 468).
\end{abstract}

É a partir da sugestão da tutora que a menina começa a registrar suas impressões e reflexões sobre as pessoas com quem convive e, principalmente, sobre ela mesma, construindo, nas páginas de seu diário, uma narrativa de si. Tal narrativa, contudo, revela-se um local em que, ao se construir como sujeito a partir de suas memórias e seus pensamentos, Porfiria acaba por apagar os limites que a distinguem de Miss Fielding, não apenas pelo fato de que, aos olhos da mulher, a letra da menina tentava imitar a sua, mas principalmente porque a moça encontra a narrativa de sua vida nas páginas do diário:

Pensé que si no lo leía, tal vez el diario dejaría de existir; yo rompería su encantamiento, ignorándolo. (...)

Todas las cosas que me han sucedido las leo en este diario.

(...)

Hablará por mí el diario de Porfiria Bernal. Me falta vivir sus últimas páginas (OCAMPO, 2007, p. 477, grifo meu).

Seja pela similaridade da letra, seja pelo fato de o texto de Porfiria relatar o que Antonia vive ou mesmo pela afirmação de que as palavras do diário da criança "falam" pela mulher, o espelhamento de identidades aqui verificado denota uma concepção que rompe radicalmente com as premissas de contenção e unidade que regem o imaginário patriarcal a respeito do corpo feminino, fazendo ecoar a já citada metáfora do fluido, proposta por Luce Irigaray, uma vez que, como me parece lícito afirmar, as personagens apresentadas no conto de Silvina Ocampo, ao fim e ao cabo, são "sempre uma e outra, ao mesmo tempo. (...) Sem limites nem bordas" (IRIGARAY, 2017, p. 245).
Corpo sem fim, escrita sem margem 
Rafael Eisinger

Guimarães

É curioso observar que a escolha do verbo "falar", tendo em vista a reflexão aqui levada a cabo, não representa de forma alguma um ato aleatório. Isso porque, diante do enigmático fato de que, segundo Miss Fielding, o diário da menina segue sendo escrito mesmo enquanto está em posse da tutora, as próprias páginas do caderno de Porfiria dão uma explicação, ainda que fantástica, para o fato: "Es como si una voz me dictara las palabras de este diario: la oigo en la noche, en la oscuridad desesperada de mi cuarto" (OCAMPO, 2007, p. 477). Se penso, junto com Irigaray, no caráter "fluido" da voz, em detrimento da "solidez" que marca a racionalidade e a palavra escrita, a presença desse elemento como sugestão de origem e fonte do relato lido por Antonia - relato esse que pode ser fruto tanto da experiência de Porfiria quanto da sua própria, ou, ainda, da experiência de ambas - remete a um aspecto muito caro à perspectiva feminista, qual seja, a irrelevância e mesmo a não necessidade de marcar a autoria do discurso.

Valendo-se de estratégias narrativas distintas, "Autobiografía de Irene" também instaura uma problematização na compreensão monolítica e homogênea sustentada pela cultura patriarcal em relação ao corpo. Na trama, a protagonista é uma moça de 25 anos portadora de uma estranha condição: ser capaz de prever o futuro. Contudo, tal aptidão faz com que ela não consiga reter suas memórias, sendo o único remédio para isso a sua morte, o que faz desta um momento aguardado com ansiedade pela personagem, como se observa no parágrafo que inicia o conto:

\footnotetext{
Ni a las iluminaciones del veinticinco de mayo, en Buenos Aires, con bombitas de luz en las fuentes y en los escudos, ni a las liquidaciones de las grandes tiendas con serpentinas verdes, ni al día de mi cumpleaños, ansié llegar con tanto fervor como a este momento de dicha sobrenatural (OCAMPO, 2007, p. 158).
}

De posse da informação acerca dessa condição peculiar de Irene, pode chamar a atenção do leitor o fato de o conto apresentar, como insinua o título, um relato pormenorizado de diversos momentos da vida da personagem narrados em primeira pessoa. Ou seja, se a protagonista é incapaz de reter suas memórias, como ela consegue relatá-las? A resposta, fortemente marcada pelo insólito, é apresentada ao final da narrativa, quando a moça, sentada em um banco de praça, inicia um diálogo com uma mulher que se acomoda a seu lado e começa a falar sem 
revelar seu rosto. Embora seja uma desconhecida, após poucos minutos de conversa, a estranha afirma que, de alguma forma, a moça que acaba de conhecer lhe é familiar:

- ¡Irene, me parece que la conozco desde hace mucho tiempo! He visto su rostro en alguna parte, tal vez en una fotografía, con un peinado alto, con cintas de terciopelo y un sombrero con guindas. ¿No existe una fotografía suya, con un fondo melancólico de árboles? ¿Su padre no vendía plantas hace tiempo? ¿Por qué quiere morirse? No baje los ojos. ¿No admite la belleza del mundo? Usted desea morir porque en las despedidas todo se vuelve más definitivo y hermoso (OCAMPO, 2007, p. 170).

Corpo sem fim, escrita sem margem

Os elementos sumarizados pela voz feminina correspondem a alguns dos episódios que, a despeito da incapacidade de memorização de Irene, são narrados pela protagonista ao longo do conto, instaurando, a exemplo do que se passa em "El diario de Porfiria Bernal", uma relação de espelhamento e duplicidade entre duas figuras femininas. E é justamente essa voz sem corpo, fluida, diria eu, que se encarrega de contar a história de Irene:

- Irene Andrade, yo quisiera escribir su vida.

- ¡Ah! Si usted me ayudase a defraudar el destino no escribiendo mi vida, qué favor me haría. Pero la escribirá. Ya veo las páginas, la letra clara, y mi triste destino. Comenzará así:

Ni a las iluminaciones del veinticinco de mayo, en Buenos Aires, con bombitas de luz en las fuentes y en los escudos, ni a las liquidaciones de las grandes tiendas con serpentinas verdes, ni al día de mi cumpleaños, ansié llegar con tanto fervor como a este momento de dicha sobrenatural.

Desde mi infancia fui pálida como ahora... (OCAMPO, 2007, p. 171, grifo da autora).

Como se pode depreender a partir desse excerto, que encerra o conto reproduzindo justamente seus parágrafos iniciais, o texto de Silvina Ocampo instaura uma indefinição quanto à autoria do relato, problematizando, a exemplo do que se passa com "El diario de Porfiria Bernal", a premissa de "propriedade do texto" que pauta o pensamento 
patriarcal. Mais que isso, se forem levados em consideração o uso do termo "autobiografia" no título e o fato de termos uma narradora autodiegética, parece bastante plausível cogitar que a voz sem rosto trata-se de uma projeção de Irene, uma espécie de duplo de si. Nesse sentido, é possível aqui também se pensar em uma subversão da ideia de corporeidade estabelecida hegemonicamente, na medida em que essa subjetividade feminina transcende os próprios limites físicos de seu corpo para poder construir, a partir da narrativa, sua própria identidade.

Rafael Eisinger

Guimarães

216

\section{Considerações finais}

A civilização e o imaginário ocidentais, que tiveram no patriarcado e no sexismo seus alicerces mais consistentes, construíram e reproduziram, por séculos, uma subjugação física e simbólica das mulheres, utilizando para isso, dentre outras estratégias, uma pretensa associação do feminino à natureza, ao corpóreo e ao imanente, garantindo ao masculino a vinculação com as esferas da cultura, da razão e da transcendência. Tal inferiorização do feminino assume, no âmbito da arte e da cultura, a forma de um não reconhecimento das mulheres como sujeitos do discurso, relegando-as aos status de musa inspiradora ou de objeto de adoração.

Mesmo que seja possível localizar uma série de exemplos de mulheres que, desde a Antiguidade, rompiam já com o silêncio e a inação que lhes eram impostos, é a partir do século XIX que elas consolidam seu papel como escritoras. Ao se apropriarem da voz da narrativa, antes tida como propriedade exclusiva do masculino, essas mulheres, por óbvio, desenvolveram também uma linguagem literária própria, um jeito de narrar distinto do masculino, o qual advinha de sua experiência de gênero que é também distinta da masculina. Curiosamente, a passagem da situação de corpo narrado para a de voz que narra, no caso de muitas escritoras, não significou um abandono da questão corporal, elemento ao qual a identidade feminina foi aprisionada pelo masculino. Muito pelo contrário, foi justamente a partir de uma reflexão acerca da própria corporalidade, elemento que promove uma ruptura na lógica do pensamento hegemônico, que muitos textos de autoria feminina instauraram uma problematização e um redimensionamento em alguns dos pontos nevrálgicos do imaginário androcêntrico, tais como a questão da beleza como atributo inerente ao corpo feminino e a concepção do corpo como algo dado, uno e fechado. 
No caso da obra da escritora argentina Silvina Ocampo, em especial nos contos "Autobiografía de Irene" e "El diario de Porfiria Bernal", as histórias das protagonistas são contadas por elas próprias. Em um ato de usurpação da autoridade/autoria masculina, Irene, Antonia e Porfiria olham para si e refletem sobre sua condição, construindo suas identidades no próprio ato de narrar. Elas inventam a si mesmas por meio das próprias palavras, por meio de suas próprias vozes, de forma fluida, plural e incontida.

Assim, subvertendo a lógica androcêntrica tanto na forma quanto no conteúdo, Silvina Ocampo, nos referidos contos, põe em xeque muitas das premissas que sustentam a concepção patriarcal, não apenas com relação ao objeto literário - em textos que desestabilizam a ordem narrativa, valendo-se do recurso da circularidade e da sobreposição de

Corpo sem fim, escrita sem margem

\section{REFERÊNCIAS}

BEAUVOIR, Simone de. 0 segundo sexo. Traduzido por Sérgio Milliet. 2. ed. Rio de Janeiro: Nova Fronteira, 2009.

BOURDIER, Pierre. A dominação masculina. Traduzido por Maria Helena Kühner. 2. ed. Rio de Janeiro: Bertrand Brasil, 2002.

CIXOUS, Hélène. The Laugh of the Medusa. Signs, v. 1, n. 4, p. 875893, 1976.

DALLERY, Arleen B. A política da escrita do corpo: écriture féminine. In: BORDO, Susan R.; JAGGAR, Alison M (Org.). Gênero, corpo, conhecimento. Tradução de Britta Lemos de Freitas. Rio de Janeiro: Record: Rosa dos Tempos, 1997, p. 62-78. 
GROSZ, Elizabeth. Corpos reconfigurados. Cadernos Pagu, Campinas, n. 14, p. 45-86, 2000.

GUERRA, Lucía. La mujer fragmentada: historias de un signo. 3. ed. Santiago de Chile: Editorial Cuarto Propio, 2006.

IRIGARAY, Luce. Este sexo que não é só um sexo: sexualidade e status social da mulher. Traduzido por. São Paulo : Editora Senac São Paulo, 2017.

Rafael Eisinger

Guimarães

OCAMPO, Silvina. Cuentos completos I. 2. ed. Buenos Aires: Emecé Editores, 2007.

ORTNER, Sherry. Está a mulher para o homem assim como a natureza para a cultura. IN: ROSALDO, Michelle Zimbalist; LAMPHERE, Louise (Org.). A mulher a cultura e a sociedade. Traduzido por Cila Ankier e Rachel Gorenstein. Rio de Janeiro: Paz e Terra, 1979, p. 95-120.

RICHARD, Nelly. Intervenções críticas: arte, cultura, gênero e política. Belo Horizonte: UFMG, 2003.

SCHMIDT, Rita Terezinha. Descentramentos/convergências: ensaios de crítica feminista. 1. ed. Porto Alegre: Editora da UFRGS, 2017.

SHOWALTER, Elaine. A crítica feminista no território selvagem. Traduzido por Deise Amaral. In: HOLLANDA, Heloisa Buarque de (org.). Tendências e impasses. Rio de Janeiro: Rocco, 1994, p. 23-57.

WOOLF, Virginia. Um teto todo seu. Traduzido por Vera Ribeiro. Rio de Janeiro: Círculo do Livro, 1990. 